Meta

Journal des traducteurs

Translators' Journal

\title{
Traduction et modèles canoniques : l'angoisse de la désobéissance
}

\section{Maria Cristina Batalha}

Volume 45, numéro 4, décembre 2000

URI : https://id.erudit.org/iderudit/001999ar

DOI : https://doi.org/10.7202/001999ar

Aller au sommaire du numéro

\section{Éditeur(s)}

Les Presses de l'Université de Montréal

ISSN

0026-0452 (imprimé)

1492-1421 (numérique)

Découvrir la revue

Citer cet article

Cristina Batalha, M. (2000). Traduction et modèles canoniques : l'angoisse de la désobéissance. Meta, 45(4), 569-579. https://doi.org/10.7202/001999ar

\section{Résumé de l'article}

Au cours de l'histoire, la circulation des textes s'est opérée par l'intermédiaire de leurs traductions, lesquelles, bonnes ou mauvaises, sont partie prenante du patrimoine littéraire de tous les pays, indépendamment du découpage "national " qu'on en fait habituellement. Néanmoins, loin d'être des opérations gratuites ou aléatoires, les stratégies mises en œuvre au moment de la traduction sont porteuses d'un sens politique et révèlent des poétiques canoniques que l'œuvre traduite vient confirmer ou refuser. Ainsi, étudier les différentes réceptions d'un texte étranger, l'impact provoqué et les nouveaux textes qu'il a contribué à engendrer à partir de ces lectures représentent-ils un champ privilégié pour les études littéraires. Sous cet angle, l'examen d'une littérature étrangère prend les allures d'une littérature comparée, notamment lorsqu'il s'agit d'une relation impliquant des pays de niveaux de développement différents, tel le Brésil face à la production européenne. 


\title{
Traduction et modèles canoniques : l'angoisse de la désobéissance
}

\author{
MARIA CRISTINA BATALHA \\ Université de l'État de Rio de Janeiro, Rio de Janeiro, Brésil
}

\begin{abstract}
RÉSUMÉ
Au cours de l'histoire, la circulation des textes s'est opérée par l'intermédiaire de leurs traductions, lesquelles, bonnes ou mauvaises, sont partie prenante du patrimoine littéraire de tous les pays, indépendamment du découpage «national» qu'on en fait habituellement. Néanmoins, loin d'être des opérations gratuites ou aléatoires, les stratégies mises en œuvre au moment de la traduction sont porteuses d'un sens politique et révèlent des poétiques canoniques que l'œuvre traduite vient confirmer ou refuser. Ainsi, étudier les différentes réceptions d'un texte étranger, l'impact provoqué et les nouveaux textes qu'il a contribué à engendrer à partir de ces lectures représentent-ils un champ privilégié pour les études littéraires. Sous cet angle, l'examen d'une littérature étrangère prend les allures d'une littérature comparée, notamment lorsqu'il s'agit d'une relation impliquant des pays de niveaux de développement différents, tel le Brésil face à la production européenne.
\end{abstract}

\begin{abstract}
Throughout history, the dissemination of texts has been possible by means of their translations. These, whether good or bad, are an integral part of a common stock of literary works, independent of a nationalistic focus which is so often made. However, far from being gratuitous textual operations, the various strategies which are activated in the acts of translating are politically revealing options and denounce canonical poetics in practice, which the translated work either reinforces or challenges. Therefore, studying the various ways in which a foreign text has been received in a particular country in order to evaluate the impact which it has generated, as well as any new texts which may have derived from these readings, is a privileged ground for literary studies. Seen from this point of view, the study of foreign literature assumes the aspect of comparative literature, especially when the comparison involves countries at a different level of development, which is often the case when works are translated into Brazilian Portuguese.
\end{abstract}

\section{MOTS-CLÉS/KEYWORDS}

modèle canonique, littérature nationale, littérature traduite, système littéraire, fidélité

Les styles sont collectifs et passent d'une langue à l'autre; les œuvres, elles, toutes enracinées dans leur sol langagier, sont uniques... Uniques, mais non isolées: chacune d'entre elles naît et vit en rapport aux autres œuvres en langues différentes. Ainsi, ni la pluralité des langues ni la singularité des œuvres ne signifient hétérogénéité irréductible ou chaos, bien au contraire: c'est un monde de relations fait de contradictions et de correspondances, d'unions et de séparations.

OCTAVIO PAZ (1981)

Chaque fois que nous nous penchons sur la culture de l'autre, nous sommes amenés à réfléchir sur nous-mêmes et sur la manière dont nous prenons position face à cet autre. Ce travail consistera donc en une réflexion sur le type de relation qui s'établit lorsque deux cultures se retrouvent côte à côte et que la traduction est le véhicule 
de cet échange. Il nous semble évident que l'acte de traduire renferme déjà en luimême l'idée implicite de la souveraineté de toutes les langues du monde. Le langage du traducteur opère une "créolisation» — pour nous en tenir à l'expression de l'écrivain antillais Édouard Glissant (1996) — en ce sens que toute langue, dans son rapport avec le monde, produit l'«imprévisible». C'est grâce au fruit de cette imprévisibilité que sont nées les premières grandes œuvres de la littérature européenne occidentale, notamment à l'époque de la Renaissance où l'activité de traduction se trouvait intimement liée à celles de l'imitation et de la création.

Or, réfléchir sur le pont qui nous mène à l'autre s'avère donc d'autant plus fondamental que, comme le souligne Yves Chevrel (1989: 18): «Traduire, éditer une traduction, n'est pas seulement une opération d'ordre linguistique, c'est aussi prendre une décision qui met en jeu un équilibre culturel et social: traduire la Bible a été, et reste, une opération d'ordre idéologique et politique.»

Nous considérons que, d'une part, la mondialisation promeut le rapprochement entre les langues et que, d'autre part, nous sommes aussi fortement marqués par des préjugés dont nous héritons passivement et contre lesquels nous avons du mal à lutter. Conformément à ce qu'a dit Glissant, nous ressentons un rapport à la fois de domination et de fascination face à la langue des pays technologiquement très développés; en contrepartie, on tend à rejeter sur le plan du folklorique et de l'exotique les autres langues, en particulier celles qui ne possèdent pas d'écriture (Glissant 1983). La manière dont nous envisageons la culture et la langue que nous traduisons est révélatrice d'un positionnement idéologique face à cette langue de départ, de même que, lorsque nous avons affaire à la culture de l'autre, c'est avant tout sur nous-mêmes que reposent nos réflexions. C'est donc par rapport à l'autre que nous percevons de façon plus nette le statut de notre différence dans le cadre de ce que nous appelons génériquement la culture universelle.

Or, en prenant comme point d'observation les différentes sociétés et leurs manifestations culturelles, Wolfgang Iser (1992) souligne la nécessité d'une perspective «interculturelle» plutôt que celle du comparatisme communément pratiquée. L'analyse comparatiste risquerait de mener à des superpositions de cultures et d'engendrer des notions de hiérarchie. Considérer l'espace entre cultures, c'est en même temps, affirme-t-il, créer un « espace pour une auto-réflexion ». En fait, du moment où nous reconnaissons l'autre en tant que tel dans son altérité, nous mettons à l'œuvre le potentiel de «traduisibilité» qui va à l'encontre des notions de «cannibalisme», d'«appropriation» ou d' «assimilation». La traduisibilité — expression des différentes manières à travers lesquelles l'altérité se manifeste — crée une voie à double sens entre les cultures, étant donné que l'altérité n'est compréhensible que lorsqu'on prend sa propre culture comme point de repère, et que celle-ci, à son tour, se modifie par le contact avec l'autre. C'est la négociation permanente entre l'«étrangeté » et la «familiarité », entre le «connu» et le «méconnu» qui représente à la limite le moyen par lequel les systèmes culturels s'organisent et se transforment. Si l'on retient, par exemple, le contexte d'apprentissage d'une langue étrangère, il semble par trop évident de nos jours que celle-ci passe nécessairement par le filtre de la langue maternelle, ce qui a d'ailleurs contribué à la réhabilitation de l'exercice de traduction en classes de langue à l'heure actuelle. En outre, cette pratique permet également d'entamer une réflexion enrichissante sur les mécanismes et les particularités de notre propre langue par rapport à la plage d'interface qui se dessine entre les diverses 
langues et cultures. Dès lors, la traduction peut jouer un rôle rénovateur et vernaculisant. Ce rôle qui lui est assigné a été soulevé par l'écrivain et critique Osman Lins (cité dans Paes 1990: 11) au sujet de la réalité de la littérature brésilienne: "L'écrivain brésilien, plus que tout autre écrivain d'expression française ou saxonne, ressent le besoin impérieux de fréquenter les autres littératures. Telle fréquentation peut se produire par la maîtrise d'autres langues. Je pense cependant que les résultats sont nettement supérieurs lorsque l'écrivain dispose d'un nombre considérable d'œuvres bien traduites. Non seulement par le fait que ce n'est que très rarement que l'écrivain maîtrise plusieurs idiomes, mais aussi parce que le contact avec le texte traduit (et la traduction tend à exercer une pression rénovatrice sur les structures linguistiques du pays récepteur) permet une lecture plus agile, outre l'avantage de mettre le lecteur d'une œuvre étrangère en contact avec sa propre langue.»

Il conviendrait donc de signaler que c'est par l'intermédiaire de la traduction que la plupart des œuvres franchissent les frontières d'une culture et ouvrent la voie à leur incorporation à la culture de la langue d'arrivée, notamment par le jeu d'intertextualité qui se déclenche.

S’il n'en était pas ainsi, comment pourrait-on concevoir la formation de la plupart des littératures des pays colonisés par des métropoles européennes, sans compter les contributions et le legs gréco-romains, les romans de chevalerie, les épopées de la Renaissance et tant d'autres textes qui ont circulé par l'intermédiaire de leur traduction? Dans la période de formation des littératures occidentales européennes, les traductions ont bien souvent été patronnées par des monarques puissants qui y voyaient la possibilité d'enrichir et d'émanciper les langues nationales. On ne saurait oublier l'exemple de François I ${ }^{\mathrm{er}}$, le grand promoteur de la Renaissance française, qui aimait les traducteurs et finançait leur travail.

Néanmoins, si la traduction des textes étrangers a contribué à l'enrichissement du patrimoine culturel commun à tous les hommes, celle-ci a également été mise au service d'objectifs divers tout au long de l'histoire millénaire de ce type de pratique. En effet, la façon d'envisager la langue et la culture que nous traduisons révèle un parti pris idéologique devant cette langue et cette culture - ainsi que notre statut par rapport à notre différence - et cette prise de position implique une manière spécifique de traduire.

En fait, le traitement que les textes ont reçu à travers leurs traductions, leur appropriation ou les fruits engendrés par le contact avec les différentes cultures locales n'ont pas eu lieu de façon innocente ni aléatoire. Aussi, ce traitement est-il loin d'être uniforme et varie-t-il selon l'époque, le pays et les objectifs auxquels les textes traduits se destinaient. Dès lors, à travers le temps, des stratégies diverses telles que l'«emprunt» ou la «domestication » ont été mises en œuvre afin d'accomplir positivement les buts assignés.

Ainsi, la stratégie de l'emprunt, c'est-à-dire le maintien des termes de l'original et des particularités culturelles, a été utilisée différemment au cours de l'histoire. On citerait le cas de la Grèce qui, dominée par les Romains, a contribué fortement à une langue et à une littérature latines enrichies par la traduction des textes grecs.

L'emprunt a été poussé à l'extrême par Ezra Pound, par exemple, dans les Cantos, où la traduction des œuvres en langues différentes cède le pas à la citation tout court et promeut l'effacement de la frontière entre la traduction et l'original. Qu'on accepte ou non les excès de Pound, force est de reconnaitre le fait qu'il a libéré 
la traduction de ses contraintes excessives et qu'il se pose comme chef de file de tout un courant moderne de la traductologie, auquel sont d'ailleurs affiliés les frères Campos, traducteurs et théoriciens brésiliens. Grâce à Pound, "le traducteur contemporain peut dorénavant choisir la position dans laquelle il va se placer dans l'échelle de fidélité à l'original» (Milton 1998: 117).

Les choix opérés gardent donc des liens étroits avec les poétiques du traducteur, qui rejoignent à la limite celles de son époque, et révèlent une prise de position dans une série littéraire donnée, à savoir que ce choix permet de déceler le degré de rénovation, voire de rupture, ou bien de confirmation à l'égard des canons existants dans lesquels l'œuvre s'inscrit.

Lorsqu'on a traduit les classiques aux Xvi ${ }^{\mathrm{e}}$ et $\mathrm{XVII}^{\mathrm{e}}$ siècles en France avec l'objectif d'imiter les auteurs antiques pour faire du français une langue littéraire, étant donné que celle-ci était déjà le moyen d'expression d'un État monarchique assez puissant, ces traductions ont subi un processus de «sélection» et le traitement qu'ont reçu les textes anciens reposait sur le principe de l'égalité, ce qui veut dire que, lorsque ces textes ont été traduits en français, toute idée d'une éventuelle supériorité des langues anciennes sur la jeune langue française avait été écartée. L'avènement des académies, notamment de l'Académie française, à cette même époque a suscité la formation de deux courants distincts quant au mode d'envisager la traduction: d'une part, ceux qui prônaient la liberté et, d'autre part, les tenants de la fidélité, à savoir la résistance à la «domestication». Dans les académies, on ajoutait, coupait et modernisait le texte original au nom du bon goût, soit de la bienséance. Alexander Fraser Tytler (Milton 1998: 38) fait paraître un livre consacré à l'art de la traduction à la fin du XVIII ${ }^{\mathrm{e}}$ siècle. Si, d'une part, il admet que le traducteur doit agir en liberté, visant surtout un objectif esthétique, d'autre part, les critères dont il se sert pour évaluer la pertinence des rajouts et/ou omissions sont fortement liés aux paramètres canoniques de l'époque, aussi bien du point de vue esthétique que du point de vue moral à une époque où régnait en souveraine la loi de la bienséance. En effet, lorsqu'il commente la traduction d'Homère faite par Pope, il applaudit l'initiative de celui-ci d' "élever» le poète grec chaque fois qu'il se sert d' «images trop basses ou trop vulgaires». Tytler trouve ainsi tout à fait légitime, voire naturel, que le traducteur ait supprimé le passage d'Homère contenant des éloges sensuels à la taille de la servante dans l'Illiade. Le souci de la pertinence ou non de certaines allusions ou références «basses» reflète l'importance attribuée au lecteur, ce qui conforte notre point de vue que la réception est inscrite dans la production culturelle de toute période, intégrant ainsi le maillon du système littéraire d'une époque donnée. En fait, le traducteur tente de plaire à la jeune classe moyenne anglaise de la fin du XVII ${ }^{\mathrm{e}}$ siècle dont il s'applique à ne pas choquer le goût en évitant des références qui ne seraient pas de mise. Cette tendance sera poussée à l'extrême dans la France du XVII ${ }^{\mathrm{e}}$ siècle, moment culminant des «belles infidèles », où le culte de la beauté était directement associé à la notion de clarté et de précision. Aussi, le traducteur supprime-t-il les impropriétés tant d'ordre moral que stylistique, comme le suggèrent les observations de Boileau: «Il fallait respecter l'usage, et prenoit bien garde à ne point choquer la délicatesse de notre langue par des termes barbares et étrangers. » (Boileau, cité dans Milton 1998: 58).

Réagissant aux instances officielles qui définissaient les canons, les œuvres traduites à Port-Royal faisaient preuve de rigueur et de fidélité formelle aux textes 
d'origine, attitude qui reflétait bien la manière dont les jansénistes envisageaient tout ce qui se rattachait à la religion et à la morale (Delisle et Woodsworth 1998: 52). Considérons ainsi l'exemple de Dominique Bouhours, théoricien français rattaché à l'Académie, qui court à la défense ethnocentrique de la langue française en tant que miroir de la vérité: «Notre langue n'emploie que très sobrement les hyperboles, car celles-ci sont des figures ennemies de la vérité; en cela elle s'en tient à notre humour franc et sincère qui ne saurait tolérer la fausseté ni le mensonge.» (Bouhours, cité dans Lima 1996: 32).

Écrit au XVII ${ }^{\mathrm{e}}$ siècle par un jésuite, il ne nous semble pas étonnant que le critique propose un découpage sélectif des apports de la culture classique à une époque où le concept canonique de "vraisemblence» est appelé à contribuer à la crédibilité de la littérature en tant qu'une des expressions les plus dignes de l'État français, représenté par la figure de Louis XIV, dont le règne servait de modèle à d'autres monarques européens. Cette entreprise se revêt, dans le cas de l'évangélisation jésuite, du besoin d'opposer le principe chrétien de vérité révélée à celui de mensonge, auquel la littérature risquerait de servir de support légitimateur.

Les décrets politiques édictés pendant la Révolution ont été traduits dans tous les langues régionales parlées en France, ce qui permettait à tous les citoyens d'être informés des nouvelles règles de la politique de l'État et constituait donc l'application du statut d'égalité entre toutes les langues parlées dans les différentes régions, rejoignant ainsi les principes majeurs de l'idéal du mouvement. Postérieurement, en raison de la terminologie révolutionnaire récente et, par conséquent, sans correspondant dans ces langues, on a pris la décision d'imposer une seule langue «nationale» à toute la population (Brunot, cité dans Delisle et Woodsworth 1998: 219-220).

William Caxton, au $\mathrm{xvi}^{\mathrm{e}}$ siècle, a traduit en anglais l'Énéide de Virgile à partir d'une traduction française et il a préservé une «saveur française »; pareillement, lorsqu'il a publié les romans du cycle arthurien de sir Thomas Malory, il a introduit des modifications de style pour le rendre plus «typiquement français», compte tenu de l'importance de la langue et de la littérature françaises qui fournissaient les modèles canoniques de l'époque.

Quant au Brésil, nous estimons que le fait d'avoir été colonisés par le Portugal — métropole dont le prestige était déjà très en baisse par rapport aux centres européens de production culturelle - nous incite à vouloir nous débarrasser de son influence pour affirmer notre identité. La volonté à tout prix de marquer notre différence par rapport au Portugal nous amène, en premier lieu, à une vision en porte-à-faux de la réalité brésilienne. Ensuite, nous finissons par retomber sous une autre forme de dépendance lorsque nous adoptons le modèle français (Mello 1997).

Dans son História da literatura brasileira, Ślvio Romero (1980: 57) met en évidence l'influence du romantisme français sur la littérature brésilienne: «La troisième phase [du romantisme brésilien], qui débute avec le romantisme politique de Constant à l'époque de notre indépendance, avec le retrait du premier Empereur, et à force d'imitation des Français, a eu le mérite de nous écarter de la stérilité littéraire des Portugais.» Il ajoute (1980: 54) : «Plus un auteur ou un politicien aura travaillé en faveur de la définition de notre caractère national, plus il aura du mérite. Celui qui aura été un simple imitateur du modèle portugais n'aura pas vraiment agi et ne sera qu'un écrivain nul.» 
Colonisés par une métropole qui se trouvait elle-même en décalage par rapport aux modèles canoniques européens, nous avons gardé le sentiment d'avoir hérité d'une langue sans prestige. À ce titre, la «créolisation» de la langue portugaise que nous avons opérée au Brésil, loin de nous paraître une hérésie, s'est bien au contraire investie du poids d'une rupture et de l'affirmation d'une singularité.

En fait, l'élément linguistique s'avère d'une importance capitale dans le processus d'affirmation des nationalités qu'instaure la période romantique. Ainsi, dans un article de journal, Gonçalves Dias (cité dans Coutinho 1980: 53), un des promoteurs du romantisme brésilien, dira très ironiquement: «Les huit ou neuf millions de Brésiliens auront-ils le droit d'augmenter et d'enrichir la langue portugaise, tout en l'accommodant à leurs besoins tels les quatre millions d'habitants vivant au Portugal? Car, si l'on veut introduire une entreprise au Brésil, devons-nous attendre qu'on nomme d'abord les mille idées qu'elle suscite? [...] Qu'on le veuille ou non la langue tupi a lancé des racines profondes dans le portugais que nous parlons et nous ne pouvons, ni ne devons, le rejeter sous prétexte que quelques mots paraissent à certains un peu durs ou barbares. Contre cela protesteraient notre Flore, notre Zoologie, notre Géographie.»

Face au besoin de construire une image identitaire, à la manière d'autres pays qui tentaient de définir les paramètres de leur identité nationale, le Brésil se heurtait à un obstacle incongru: on parlait la même langue que l'ancien colonisateur. Et on ne saurait oublier le débat qui s'est instauré à l'époque sur la possibilité ou non d'avoir une littérature propre étant donné que la langue d'expression de cette littérature ne l'était pas. La solution trouvée n'a pas tardé: nous avons une nature tropicale capable d'inspirer nos poètes et d'arriver à une littérature nationale par le thème, soit le contenu, même si le véhicule de cette littérature est une langue adoptée. Et ce sera cet atout que les écrivains mettront à l'œuvre pour chanter le mode de vie et les traditions brésiliennes et élaborer ainsi le récit cosmogonique de la geste nationale.

Les douze chants du poème épique «La confédération des Tamoios », de Gonçalves de Magalhães racontent le conflit entre les Indiens et les colonisateurs, transformant cet épisode de l'histoire passée en instant fondateur d'une nouvelle race, fruit de ce qu'il y avait de meilleur dans chacune d'elles: d'un côté, ingénuité et bonté et là le mythe du «bon sauvage» y joue un rôle important — et, de l'autre côté, sagesse de la «civilisation" portugaise légitimée par la loi. Après tout, c'était bien la recette que nous avait indiquée Ferdinand Denis — responsable de la Bibliothèque Sainte-Geneviève, à Paris, et "source de consultation» à la fois légitimée et légitimatrice non seulement pour tous ceux qui veulent connaître le pays mais pour des Brésiliens eux-mêmes - et qui devait servir à la consommation tant interne qu'externe.

Et il ne nous semble pas un hasard qu'entre 1882 et 1885 aient été publiées deux traductions italiennes du poème de Magalhães. En fait, il était intéressant pour l'Italie que des masses de travailleurs agricoles désœuvrés puissent trouver dans le Nouveau Monde une possibilité de vie meilleure. Le poème vient donc contribuer à la propagande pour attirer ce contingent émigrant qui y voyait l'image d'un pays qui se développe et se modernise, associé à l'abondance, à l'exubérance et à la richesse.

Dans le programme littéraire que nous propose Denis, il reviendrait à la jeune nation d'emprunter la route du progrès de la civilisation dont le modèle se situait en Europe, sans que disparaissent pour autant les marques «originelles» de la «terre 
américaine », c'est-à-dire que le cadre paradisiaque de nos forêts tropicales et l'exotisme devaient y figurer impérieusement.

Ces marques pittoresques restent toujours obligatoires dans l'horizon d'attentes que se créent les lecteurs et c'est grâce à elles que l'écrivain Jorge Amado a tant de succès en France si bien que, sitôt parus au Brésil, ses livres sont immédiatement traduits en français. La traduction que fait le poète Blaise Cendrars du livre A Selva - Forêt vierge, paru en 1938, atteste de la permanence de la vision du chroniqueurvoyageur qui servait de médiateur entre les deux cultures et était à la limite le responsable de la formation du mythe de l'exotisme du pays tropical. Dans la traduction de Cendrars de l'œuvre de Ferreira de Castro, les transformations, les rajouts et les découpages vont dans le sens d'un idéal de transparence permettant au lecteur français de se sentir familiarisé avec l'univers culturel du texte, car le traducteur aura déjà fait la sélection de tout ce qui pourrait ou non intéresser ce lecteur étranger. S’il n'en avait pas été ainsi, c'est-à-dire si le traducteur avait emprunté le chemin de la fidélité, se demande ironiquement Adalberto de Oliveira Souza (1995: 24), l'œuvre aurait-elle connu le même succès? En fait, ce que nous montre le critique, c'est la présence dans la traduction de Cendrars du style de celui-ci, de ses idées et de sa vision du monde. Dès lors, cette attitude contribue au confortement d'une lecture eurocentrique préconçue, qui accorde le privilège à l'univers de la langue d'arrivée au détriment de la culture où s'inscrit le texte traduit. Or, l'idéal de la transparence est dénoncé par Henri Meschonnic (1972: 308-309): "L'illusion de la transparence appartient au système idéologique caractérisé par les notions liées d’hétérogénéité entre la pensée et le langage, de génie de la langue, du mystère de l'art - notions fondées sur une linguistique du mot et non du système, sur les langues comme actualisations particulières d'un signifié transcendantal (projection philosophique du primat européocentrique, logocentrique, colonialiste de la pensée occidentale). Ces notions aboutissent à opposer textes et traductions, par une sacralisation de la littérature. Cette sacralisation est compensatoire par rapport à sa neutralisation politique. Cette sacralisation et cette compensation définissent le rôle social de l'esthétique. Il ressort du jeu de l'opposition idéologique entre texte et traduction une notion métaphysique, non historicisée, de l'intraduisible.»

On ne pourrait pas ignorer la portée de l'influence de la littérature française sur les écrivains brésiliens ainsi que sur la formation du goût du lecteur, notamment dans la période romantique: des poètes tels que Lamartine, Musset et Hugo étaient lus et traduits amplement, ainsi que d'autres poètes d'autres nationalités qui nous parvenaient en traductions françaises, comme l'Anglais Byron et l'Allemand Heine.

Dans son essai sur les traductions de Byron au Brésil, Onédia Barbosa (cité dans Milton 1998: 223) montre que, jusqu'en 1855, la plupart des traductions avaient été faites directement de l'anglais; cependant, après cette époque, presque toutes les traductions nous sont venues des traductions françaises. Il en est de même pour les œuvres d'Oscar Wilde qui ne nous sont parvenues que par l'intermédiaire du français. Il arrive que la sélection faite des œuvres de l'écrivain anglais à traduire en France reflète le privilège accordé au côté esthétique de celui-ci au détriment du rôle qu'il a joué en tant que critique social mordant. Lorsqu'on emprunte de manière irréfléchie une traduction à la place de l'original, on ne fait que renforcer un parti pris qui ne serait pas forcément le nôtre, outre le fait que la qualité de la traduction dépendra pour une large part de ce qu'on aura pris comme point de départ pour la traduction. 
Néanmoins, il faut reconnaître que les traductions vernaculaires n'ont exercé qu'une influence relative sur la production littéraire brésilienne et sur nos écrivains eux-mêmes. On ne saurait pourtant en dire autant en ce qui concerne le public qui, lui, se nourrissait de traductions, d'œuvres françaises à la quasi-unanimité et moulait un goût qui, à son tour, allait servir de paramètre pour le jugement de la valeur des œuvres d'auteurs nationaux (Paes 1990: 10-15).

D'élément essentiel à la formation de notre personnalité littéraire tout au long du XIX $^{\mathrm{e}}$ siècle et de langue de résistance avant l'indépendance du pays, le français commence à exercer une influence nuisible au début de la période républicaine, devenant un instrument d'aliénation qui fournissait les canons de la mode, des arts et de la littérature, suivis de près par les élites qui dominaient la politique, l'économie et la vie culturelle du Brésil.

En effet, comme les clercs brésiliens lisaient le plus souvent directement en français, à très peu d'exceptions près, seuls les romans-feuilletons étaient traduits et non les grands romans, obéissant de la sorte à la demande du public consommateur. En 1812, sur dix traductions publiées — toutes de textes français — on constate encore la prédominance des traités de stratégies et de techniques militaires ainsi que des connaissances en médecine, à l'appui de l'École de chirurgie, de l'Académie militaire, de l'Académie de la marine et des Archives militaires alors fondées depuis peu à Rio de Janeiro, siège de l'Empire. Cependant, trois ans plus tard, neuf romans traduits sont publiés, dont huit de l'original français, ce qui met en évidence la montée rapide des romans-feuilletons venus de Paris (Cabral 1998).

En fait, la forte demande pour ce genre de littérature, qui est très vite devenue populaire parmi nous, entraîne deux types de conséquences immédiates qui interfèrent dans notre système littéraire: d'une part, elle dépasse largement la capacité de production de nos écrivains, qui en incorporent les techniques, les thèmes et les conceptions de vie caractéristiques du genre en quête de succès auprès du public mais qui, en contrepartie, sont incapables de répondre en termes quantitatifs à la soif de lecture de ce public. D'autre part, cette forte demande contribue à la mauvaise qualité des traductions qui circulaient parmi nous.

Daniel Kidder, missionnaire américain qui a vécu au Brésil autour des années 1830, attire l'attention sur les méfaits que pouvait provoquer la littérature consommée majoritairement, croyait-on, par les femmes. D’après lui, «les réserves littéraires [des femmes] consistent surtout en des romans de Balzac, Eugène Sue, Dumas, père et fils, George Sand; ce sont des intrigues de pacotille et des feuilletons dans les journaux. Voilà comment elles se préparent pour être épouses et mères » (Kidder et Fletcher, cité dans Lajolo et Zilberman 1996: 243-244). Selon le brasilianist, la raison pour laquelle il régnait un cadre général d'apauvrissement intellectuel à Rio de Janeiro était les mauvaises influences qu'y exerçait la culture française dominant le marché du livre et du journal: «N'importe quel petit feuilleton parisien se doit d'être traduit immédiatement pour être publié à Lisbonne et à Rio de Janeiro. Et le nombre de ceux qui s'adonnent à cette lecture inutile voire nuisible est tellement important que l'on ne se donne plus la peine de chercher les œuvres originales et morales. En plus, le français a occupé la place du latin parmi les Brésiliens, si bien que, pour s'inscrire aux instituts supérieurs d'enseignement, il est indispensable de parler cette langue, ce qui est d'ailleurs une pratique assez courante» (Kidder et Fletcher, cité dans Lajolo et Zilberman 1996: 209). 
En prenant la défense du français, Jean-Baptiste Debret revendique pour la culture française la responsabilité de l'amélioration du niveau intellectuel des femmes brésiliennes: «[...] l'éducation a commencé à prendre de l'impulsion et les moyens d'enseignement se sont multipliés à tel point qu'il est rare de trouver à l'heure actuelle une dame qui ne sache pas correspondre en plusieurs langues ou apprécier la lecture comme on le fait en Europe. [...] La littérature française a énormement contribué à cela, grâce à une sélection agréable de nos œuvres les plus morales traduites au portugais; ces livres, devenus classiques, intéressent par leur nouveauté, ornent les esprits et forment le cœur des jeunes étudiantes brésiliennes» (Debret, cité dans Lajolo et Zilberman 1996: 242).

À la différence des grands romans qui étaient lus dans la langue d'origine, les feuilletons se destinaient à un public qui dépendait de la commercialisation des traductions pour avoir accès à ce type de lecture. Les écrivains se retrouvaient donc partagés entre leur œuvre «sérieuse», à savoir leur œuvre «littéraire» proprement dite, et les feuilletons qu'ils écrivaient — ou traduisaient — pour les journaux pour répondre à la demande du public et à leur besoin de survie. Ils gardaient ainsi le sentiment d'être scindés en deux personnes distinctes: l'une devant subir les exigences des propriétaires des journaux au détriment de la qualité de leur travail, et l'autre préservant la pureté de ce qu'ils considéraient la « haute littérature » mais qui n'était lue que par un public très réduit. Dans ces conditions, l'écart entre ce qu'écrivent les clercs et ce que lit le public ne fait que s'approfondir et le texte littéraire commence donc à être progressivement perçu comme une création quasi divine flottant au-dessus de la réalité. Or, si le texte littéraire représentait déjà un objet sacré dû au rôle attribué à la littérature dans l'effort de construction de l'image de la Nation, le texte littéraire français - représentant d'un modèle canonique ayant laissé tant de traces dans une littérature brésilienne qui lui est fortement tributaire - semblait à nos yeux un objet magique immaculable. Cette attitude se reflètera dans le travail du traducteur qui, par peur de toucher à une langue sacralisée, souffre de l' «angoisse de la désobéissance », pour en revenir à l'expression d'Harold Bloom (1973) pour qui tout poète serait menacé de l'angoisse de la nouveauté par rapport à ses prédécesseurs. Aussi tendra-t-il à pratiquer la correspondance, voire le calque, plutôt qu'une traduction plus libre et plus créative, soit une traduction qui accorderait le privilège au contenu qui l'emporterait sur la forme, pierre d'achoppement de toute traduction poétique.

Or, comme l'a souligné Henri Meschonnic, il y a un degré d'idéologie implicite dans la théorie présupposée de l'infériorité du texte traduit par rapport à l'original ; celle-ci nous advient de tous ceux qui s'appliquent à préserver la sacralité du texte littéraire. C'est par conséquent le sentiment de l'idolâtrie de l'original qui se trouve à la base de concepts pervers de la traduction, comme «diminution», «perte» et «trahison », qui hantent la plupart des traducteurs.

Comme chacun le sait, l'État-Nation se trouve à la base de l'institutionnalisation de la littérature en tant que corps autonome, devant donc dorénavant se distinguer par le principe de la nationalité. Outre cette cause historique, l'objet littéraire, par son nouveau statut, commence à être soumis à des examens philologiques, ce qui explique l'importance que prennent les catégories de «source» et d' « influence» venant ainsi conforter l'idée de traduction comme texte inférieur (Lima 1983).

Dans le contexte périphérique où s'inscrit la culture brésilienne, les clercs intériorisent et acceptent le préjugé de retardement par rapport aux métropoles qui 
prennent la position de centres irradiateurs à partir desquels on passe à mesurer le degré de développement culturel d'un pays. La culture du pays dépendant serait alors d'autant plus avancée qu'elle serait plus proche de ce qui se produit dans ce centre. Ainsi, les rapports avec les cultures que nous prenons comme modèles impliquerontils un comportement idéologique qui repose sur deux niveaux: d'une part, il établit des hiérarchies entre les langues et, par conséquent, entre les peuples et leur culture; d'autre part, sur le plan interne, l'usage et l'appropriation des langues étrangères perçues comme «supérieures» contribuent à accentuer les différences sociales tout en confortant les instances de formation du dit "goût érudit» (voir à ce sujet Pierre Bourdieu et les essais sur le rôle des académies dans la formation du goût) au détriment des foyers de production de culture populaire qui ne réussissent pas à gagner de la visibilité.

En fait, lorsqu'au Brésil nous empruntons un mot étranger, nous tenons à le prononcer conformément à la phonétique du pays d'origine, résistant à toute tentative de «brésilianisation». La diffusion des nouveaux mots prononcés "à la manière locale» dans les médias permettrait, à mon sens, leur incorporation plus immédiate par la population en général, les rendant de la sorte une propriété commune accessible à tous indépendamment du niveau de scolarité de chacun.

Les rapports que nous établissons avec l'autre apparaissent, à divers titres, dans ce que nous consommons comme produits culturels ainsi que sur ce que nous retenons comme auteurs et/ou œuvres à traduire. Il en ressort également que la manière dont le traducteur perçoit l'acte de traduire permet de dévoiler le réseau d'implications idéologiques qui régit la production culturelle d'une époque dans un contexte sociopolitique déterminé. Et c'est dans ce sens qu’Antoine Berman (1995) affirme que l'analyse de différentes traductions d'une même œuvre nous permet d'évaluer le rôle du contexte culturel ainsi que les principes interprétatifs qui ont guidé les traducteurs dans leur travail sur le texte. Il nous propose donc de tenir compte de ces différentes traductions qui seraient à la limite autant d'objets d'étude que toute autre critique sur le texte. Il nous paraît donc évident que toute œuvre doit être comprise comme partie prenante d'un système littéraire au sein duquel apparaît un jeu de forces qui met en tension, d'une part, la reconnaissance et l'adhésion aux canons et, d'autre part, les œuvres de résistance à ces canons. Il y a donc un combat permanent entre les modèles canoniques du centre et les modèles périphériques. À ce titre, il n'existe de véritable rénovation que lorsque les modèles exclus jusqu'alors font leur irruption vers le centre et imposent dès lors un nouveau canon. Dans ce cas, la traduction des œuvres périphériques où émergent de nouveaux modèles appartenant à d'autres cultures peut contribuer au déséquilibre du système-cible en raison de l'insertion de tendances innovatrices dans la littérature du pays de la langue d'arrivée. C'est d'ailleurs grâce aux traductions de Macbeth par Deschamps et de More de Venise par Vigny, qui introduisaient de nouvelles formes et rompaient avec le règne absolu du vers alexandrin du théâtre classique français, que le théâtre romantique a pu s'imposer en France dans la première moitié du $\mathrm{XIX}^{\mathrm{e}}$ siècle, instaurant ainsi sa nouvelle esthétique et de nouveaux modèles canoniques pour la dramaturgie (Lamert et Van Bragt 1985: 149-163).

En fait, chaque fois qu'un traducteur reprend un texte pour le traduire dans sa propre langue, c'est une nouvelle singularité qui s'en dégage, car sa subjectivité, son insertion historique et sa connaissance du monde y sont forcément présentes. Les 
pertes éventuelles dans le passage d'une langue à une autre se rattrapent en gains «imprévisibles », comme le disait Glissant, et ne devraient en rien diminuer la valeur du nouveau texte produit.

Pour conclure ces réflexions sur la tâche du traducteur et sur son rôle de médiateur privilégié dans le dialogue entre les cultures — et d'épigraphe à l'envers —, je tiens à partager l'opinion de Salviano Santiago (1978: 18) sur la contribution de l'Amérique latine à la culture occidentale: «La plus grande contribution de l'Amérique Latine à la culture occidentale vient de la destruction systématique des concepts d'"unité" et de "pureté" : ces deux concepts perdent le contrôle précis de leur signification, perdent leur poids écrasant, leur marque de supériorité culturelle, à mesure que le travail de contamination des latino-américains s'affirme et s'avère plus efficace. L'Amérique Latine a inscrit sa place sur la carte du monde de la civilisation occidentale grâce au mouvement de déviation de la norme, mouvement actif et destructeur, qui transfigure les éléments donnés et immuables que les Européens exportaient au Nouveau Monde.»

\section{RÉFÉRENCES}

Arrojo, R. (1997): Oficina de tradução, $3^{\text {a }}$ éd., São Paulo, Ática.

Berman, A. (1995): Pour une critique des traductions: John Donne, Paris, Gallimard.

Bloom, H. (1973): The Anxiety of Influence, New York, Oxford University Press.

Bosı, A. (1992): Dialética da colonização, São Paulo, Companhia das Letras.

Cabral, A. do Valle (1998): "Annaes da Imprensa Nacional do Rio de Janeiro", Cadernos do Centro de Pesquisas Literárias da PUCRS, 4-3.

CÂndido, A. (1987): A educação pela noite, São Paulo, Ática.

- (1959): Formação da literatura brasileira, vol. 1 e 2, São Paulo, Martins.

Chevrel, Y. (1989): La littérature comparée, Paris, Presses universitaires de France.

Coutinho, A. (1980): Caminhos do pensamento crítico, vol. 1, Rio de Janeiro, Pallas.

Delisle, J. e J. Woodsworth (1998): Os tradutores na história, trad. Sergio Bath, São Paulo, Ática.

Glissant, É. (1996): Introduction à une poétique du divers, Paris, Gallimard.

- (1983): "Após Babel”, Correio da Unesco, 11-9.

IsER, W. (1998): "On translatability," Surface, 4.

Lajolo et Zilberman (1996): A formação da leitura no Brasil, São Paulo, Ática.

Lamert, J. et K. VAN Bragt (1985): The Manipulation of Literature, London, Theo Hermans, Croom Helm.

Lima, L. C. (1983): O controle do imaginário, Rio de Janeiro, Francisco Alves.

_- (1996): "Literatura e nação: esboço de uma releitura", Revista brasileira de literatura comparada.

Mello, M. E. C. (1997): Lições de crítica, Niterói, EDUFF.

Meschonnic, H. (1972): "Propositions pour une poétique de la traduction», Langages, 28, p. $49-54$.

Milton, J. (1998): Tradução: Teoria e prática, 2a ed., São Paulo, Martins Fontes.

PAEs, J. P. (1990): Tradução a ponte necessária, São Paulo, Ática.

PAz, O. (1981): Traducción: literatura y literalidad, Barcelona, Jusquets.

Romero, S. (1980): História da literatura brasileira, $7^{a}$ éd., Rio de Janeiro e Brasilia, José Olympio e INL.

Rouanet, M. H. (1991): Eternamente em berço esplêndido, São Paulo, Siciliano.

Santiago, S. (1978): Uma Literatura nos Trópicos: ensaios sobre sobre dependência cultural, São Paulo, Perspectiva. 